\title{
Os Objetos de Aprendizagem e o Desenvolvimento das Habilidades Espaciais
}

\author{
Wagner César Bernardes - IM/PPGEMAT/UFRGS - wcbernardes@ yahoo.com.br \\ Márcia Rodrigues Notare - IM/PPGEMAT/UFRGS - marcia.notare@ufrgs.br
}

\begin{abstract}
Resumo: Este artigo aborda o desenvolvimento das habilidades espaciais, como rotação mental, percepção espacial e visualização espacial, com a utilização de objetos digitais de aprendizagem, em alunos do Ensino Fundamental. Para analisar o potencial de alguns objetos digitais de aprendizagem no desenvolvimento das habilidades espaciais, desenvolvidos pelo Freudenthal Institute for Science and Mathematics Education (Universiteit Utrecht), foi realizada uma experiência com alunos do sexto ano do Ensino Fundamental, na qual estes deveriam realizar uma sequência de atividades propostas, a partir da manipulação destes objetos digitais. Mostramos, a partir de uma análise prévia da experiência, que as diferentes categorias de habilidades espaciais foram exploradas e que é possível iniciar um trabalho de desenvolvimento destas habilidades ainda no Ensino Fundamental.
\end{abstract}

Palavras-Chave: Habilidades Espaciais; Objetos de Aprendizagem; Geometria Espacial.

\section{Learning Objects and the Development of Spatial Skills}

\begin{abstract}
This article discusses the development of spatial skills, such as mental rotation, spatial perception and spatial visualization, with the use of digital learning objects in elementary school students. To analyze the potential of some digital learning objects in development of spatial skills, developed by Freudenthal Institute for Science and Mathematics Education (Universiteit Utrecht), an experiment was conducted with students of the sixth grade of elementary school, in which they should perform a sequence of proposed activities, from the manipulation of these digital objects. We show, from a previous analysis of the experiment, the different categories of spatial abilities were explored and it is possible to start work on developing these skills further in Elementary Education.
\end{abstract}

Keywords: Spatial Skills; Digital Technologies; Spatial Geometry.

\section{Introdução}

A experiência em sala de aula, assim como leituras cotidianas, vem evidenciando certa dificuldade dos alunos em compreender, ao longo do Ensino Fundamental e Médio, alguns conceitos de Geometria Espacial. Mais especificamente, estas dificuldades são observadas ao realizar atividades que exigem do aluno habilidades espaciais. Segundo Gutierrez (1992), diversos termos são utilizados para nos referirmos a este campo da Geometria, tais como: percepção espacial, imaginação espacial, visão espacial ou visualização.

Nos PCN's (1998) é evidenciado que, entre os objetivos do ensino fundamental, temos o de saber utilizar diferentes formas de informação e recursos tecnológicos.

Sabendo da importância de utilizar os recursos tecnológicos no espaço escolar e também de trazer significado e compreensão dos conceitos de Geometria, procurou-se utilizar objetos digitais de aprendizagem, disponíveis na internet, para auxiliar no desenvolvimento de habilidades espaciais em alunos do $6^{\circ}$ ano do Ensino Fundamental.

Nesse sentido, foram selecionados alguns objetos digitais de aprendizagem, desenvolvidos pelo Freudenthal Institute for Science and Mathematics Education, 
Universiteit Utrecht, Países Baixos (http://www.fisme.science.uu.nl/fisme/nl/), que tratam do desenvolvimento das habilidades espaciais, para trabalhar com os alunos do Ensino Fundamental.

Neste artigo, apresentamos uma experiência realizada com alunos do $6^{\circ}$ ano do Ensino Fundamental, em que os objetos digitais selecionados foram utilizados para auxiliar no desenvolvimento das habilidades espaciais. Mostramos, a partir das soluções dos alunos, as habilidades espaciais que foram desencadeadas ao longo da experiência, à luz da teoria de Choi apud Voyer, Voyer e Bryden (2005).

\section{As Habilidades Espaciais}

A habilidade espacial, para Silva (apud LOHMAN, 2010, p. 8), é definida "como a capacidade para gerar, reter, recuperar e transformar imagens visuais bem estruturadas". Choi apud Voyer, Voyer e Bryden (2005) fala sobre as categorias das habilidades espaciais, que são: rotação mental, percepção espacial e visualização espacial.

A rotação mental pode ser considerada como a capacidade de manipular, girar, torcer, ou inverter objetos bi ou tridimensionais. Um exemplo prático desta habilidade espacial seria identificar quais as duas imagens da direita que correspondem à imagem da esquerda (Figura 1).
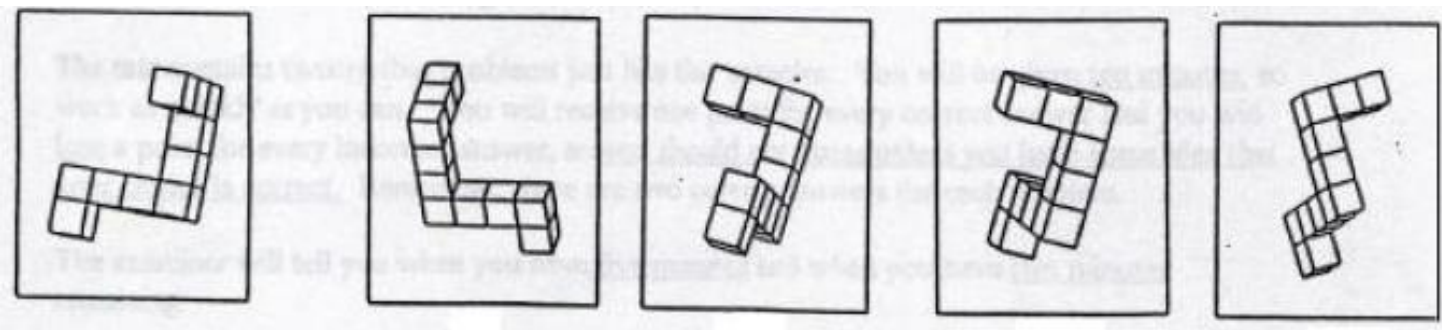

Figura 1. Exemplo de atividade que exige rotação metal

Fonte: https://www.uleth.ca/dspace/handle/10133/509

A habilidade de percepção espacial pode ser considerada como a capacidade de determinar relações espaciais mesmo em elementos dispersos. Um exemplo seria a percepção do nível de água em uma garrafa após incliná-la.

Já a visualização espacial é a capacidade de manipular informações complexas por meio de diferentes níveis. Um exemplo de situação que exige esta habilidade seria realizar uma transformação mental de um objeto bidimensional para um tridimensional.

As atividades realizadas no experimento com os alunos relatado neste artigo foram baseadas no que Gutierrez (1998) define como módulo multicubo, que é um sólido formado por vários cubos iguais ordenados, na qual suas faces sobrepõem-se. Uma vantagem dos módulos multicubos é a facilidade de trabalhar com problemas de construções de figuras sólidas a partir de suas representações planas.

A seguir, apresentaremos os diversos tipos de projeções.

Projeção em perspectiva: representação da visão real dos cubos, onde as arestas mais distantes percebem-se menores e as linhas paralelas que se distanciam parecem convergir (Figura 2). 


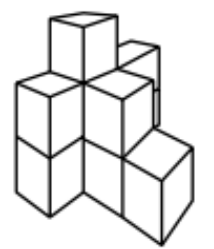

Figura 2. Exemplo de projeção em perspectiva

Projeção paralela: representação análoga à projeção em perspectiva, exceto que as linhas paralelas parecem sempre paralelas, independentemente da sua direção. Entretanto, esta representação distorce a visão real dos sólidos (Figura 3).

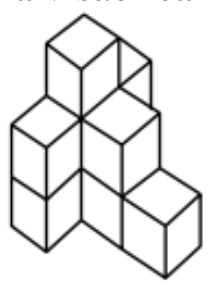

Figura 3. Exemplo de projeção paralela

Projeção isométrica: representação de um caso particular da projeção paralela. Neste caso, os cubos situam-se de tal forma que as três arestas que saem de determinado vértice se distanciam com a mesma longitude e formam ângulos de $120^{\circ}$ (Figura 4).

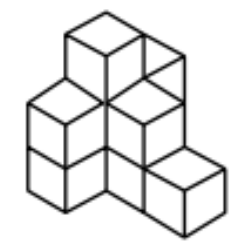

Figura 4. Exemplo de projeção isométrica

Projeção ortogonal: representação formada sobre três projeções (frente, superior, direita) dos sólidos sobre três planos ortogonais (Figura 5).

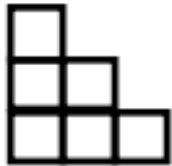

Frente

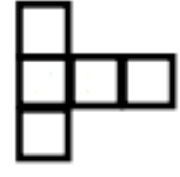

Superior

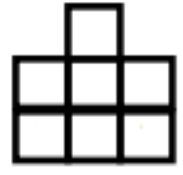

Direita

Figura 5. Exemplo de projeção ortogonal

Projeção ortogonal codificada: representação de um caso particular da projeção ortogonal, onde além das projeções, algum código é adicionado. Neste caso, a quantidade de cubos de cada fila (Figura 6).

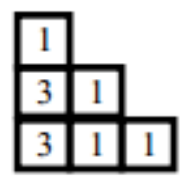

Frente

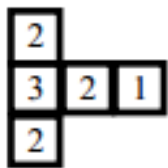

Superior

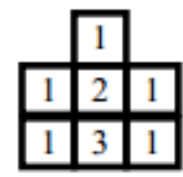

Direita

Figura 6. Exemplo de projeção ortogonal codificada

Segundo Gutierrez (1992), no ensino de Geometria Espacial, os alunos costumam apresentar dificuldades em compreender as representações no papel de 
objetos tridimensionais, pois há dois requisitos básicos para essa compreensão: interpretar a figura plana para convertê-la em um objeto tridimensional e interpretar este objeto, que, muitas vezes, é apenas uma representação mental, de um conceito geométrico real.

Neste processo de interpretar, compreender e representar as figuras espaciais, o computador, e em especial os objetos digitais, pode ser um grande aliado, pois "manipulando diretamente os objetos na tela do computador, e com a realimentação imediata, os alunos questionam o resultado de suas ações/operações, conjeturam e testam a validade das conjeturas inicialmente através dos recursos de natureza empírica" (GRAVINA, 2001, p. 89). Dessa forma, os objetos digitais podem auxiliar o aluno a criar hipóteses e estabelecer ou verificar conceitos de forma a contribuir no desenvolvimento das habilidades espaciais, pois os objetos digitais apresentados permitem a interação e a manipulação das construções. Estes podem promover um ambiente de experimentação do aprendiz para estabelecer conexões entre representações bidimensionais e tridimensionais.

\section{As Tecnologias Digitais e a Aprendizagem de Matemática}

A tecnologia é, para Vitale (1991), inevitável e historicamente necessária. Segundo este Basso e Gravina (2012, p.12) "nossas rotinas de sala de aula também deveriam incorporar, cada vez mais, as tecnologias, pois elas influem nas nossas formas de pensar, de aprender, de produzir".

Lovell (1988, p. 13) afirma que "os conceitos parecem surgir das percepções, do conhecimento real dos objetos e situações, e através da vivência de experiências e empenho em ações de diversas espécies”. Através dos objetos digitais, foi possível verificar seu papel importante na construção dos conceitos, pois os PCN's (1998, p.44) constatam que o computador tem como uma de suas finalidades constituir um "meio para desenvolver autonomia pelo uso de softwares que possibilitem pensar, refletir e criar soluções". Papert (2008) sugere que uma estratégia para melhorar a aprendizagem seria conectar o ambiente de aprendizagem por meio da cultura. Em nosso caso, podemos enfatizar a cultura do virtual, citada por Basso e Gravina (2012). Essa cultura é cada vez mais evidenciada no cotidiano escolar, onde os alunos possuem acesso a informações de uma forma rápida e fácil. Consequentemente, o professor não pode basear seu planejamento apenas com quadro e giz. Daí, a necessidade de inserir os alunos neste ambiente, na tentativa de explorar as diversas possibilidades que os objetos de aprendizagem podem oferecer.

\section{A Experiência Realizada}

Alguns objetos digitais, desenvolvidos pelo Freudenthal Institute for Science and Mathematics Education, foram desenvolvidos com o objetivo de explorar as habilidades espaciais apresentadas acima.

A habilidade de rotação mental, em diversos objetos, é explorada para solucionar os problemas propostos. Os objetos digitais utilizados, muitas vezes, possibilitavam a manipulação, de modo a rotacionar as figuras virtualmente. Entretanto, para exigir o exercício de rotação mental dos alunos, foram elaboradas atividades que, potencialmente, necessitassem desta habilidade, como a $3^{\mathrm{a}}, 6^{\mathrm{a}}$ e $8^{\mathrm{a}}$ atividades que serão descritas a seguir.

A habilidade de percepção espacial e visualização espacial foram trabalhadas em todas as atividades, mesmo que de forma indireta, visto que os objetos digitais 
permitiram a manipulação digital e possibilitaram estabelecer relações espaciais a partir das atividades.

Para verificar o potencial destes objetos digitais no desenvolvimento de habilidades espaciais, como rotação mental, percepção e visualização espacial, foi realizada uma experiência com alunos do $6^{\circ}$ ano do Ensino Fundamental em uma escola da rede municipal de Porto Alegre. A média das idades dos alunos foi de 10 a 12 anos e contou com onze participantes, selecionados através do próprio interesse e responsabilidade em participar e frequentar os encontros. No total, foram cinco encontros de $1 \mathrm{~h} 40 \mathrm{~min}$.

A coleta de dados, de caráter qualitativo, foi feita a partir de questionários denominados "abertos" que, de acordo com Fiorentini (2006, p. 116) "não apresentam alternativas para respostas, podendo o pesquisador captar alguma informação não prevista por ele ou pela literatura". Quanto ao seu caráter qualitativo, sabemos que:

Dela faz parte a obtenção de dados descritivos mediante contato direto e interativo do pesquisador com a situação objeto de estudo. Nas pesquisas qualitativas, é frequente que o pesquisador procure entender os fenômenos, segundo a perspectiva dos participantes da situação estudada e, a partir, daí situe sua interpretação dos fenômenos estudados. (NEVES, 1996, p. 1)

Além de questionários, os alunos foram acompanhados nas atividades propostas, procurando-se perceber suas estratégias frente às atividades, assim como as soluções apresentadas pelos mesmos.

A seguir, vamos descrever algumas das atividades elaboradas e algumas soluções apresentadas pelos alunos.

\subsection{Descrição das atividades}

A primeira atividade, desenvolvida com o objeto digital Building Freely, correspondeu à construção de dois objetos de casa com a utilização de cubos sobre uma malha quadriculada, como ilustra a Figura 7. Além disso, foi solicitado aos alunos que contassem o número de cubos utilizados na construção. Para realizar esta atividade, os alunos deveriam rotacionar os objetos no aplicativo, a fim de construir a base para desenvolver a habilidade de rotação mental.
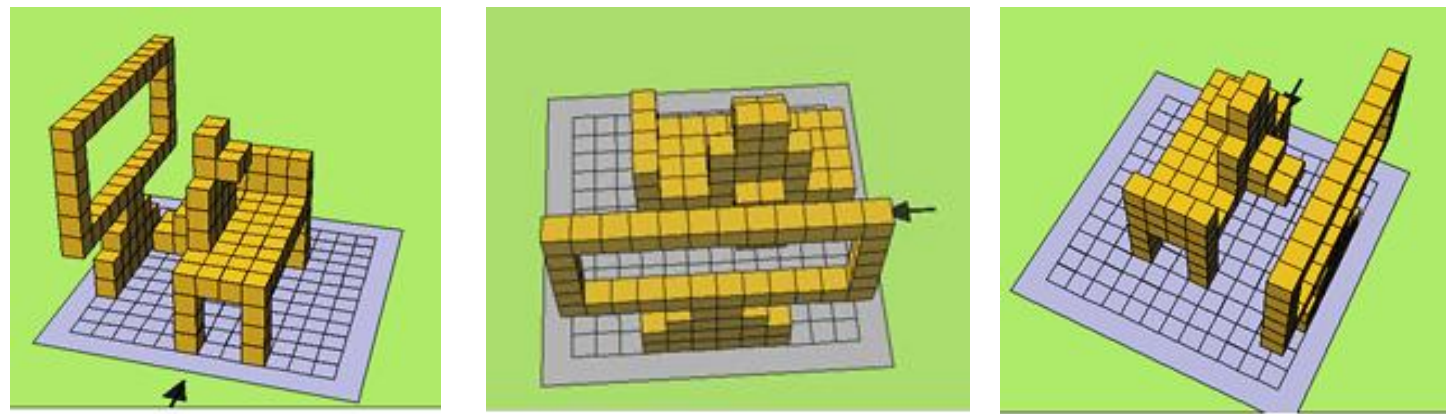

Figura 7. Três capturas de tela do aluno A.

Este objeto digital de aprendizagem permite inserir e apagar os cubos construídos, assim como também aumentar ou diminuir a área da construção. Além disso, é possível rotacionar a construção, para alterar o ponto de visualização.

Esta atividade foi introdutória e, embora, aparentemente simples, permitiu identificar algumas percepções importantes dos alunos. A primeira é que, quanto mais complexa é a figura criada, apenas duas capturas de tela do objeto não são suficientes para realizar a contagem do número de cubos utilizados na construção. Para ilustrar, 
trazemos um exemplo do aluno A, na Figura 7, cuja ideia foi construir uma cama, televisão, rack e uma pessoa interagindo no cenário.

$\mathrm{Na}$ segunda atividade, realizada com o objeto digital Copy the building, os alunos foram convidados a reproduzir determinadas construções contidas no objeto. Novamente, deveriam capturar o mínimo de visualizações necessárias para realizar a contagem dos cubos utilizados na construção. O objeto digital dá um feedback, informando quando a contagem está correta e determina automaticamente o número de cubos utilizados. As reproduções solicitadas aos alunos foram: building, stairs, pine tree e dance, como ilustra a Figura 8.
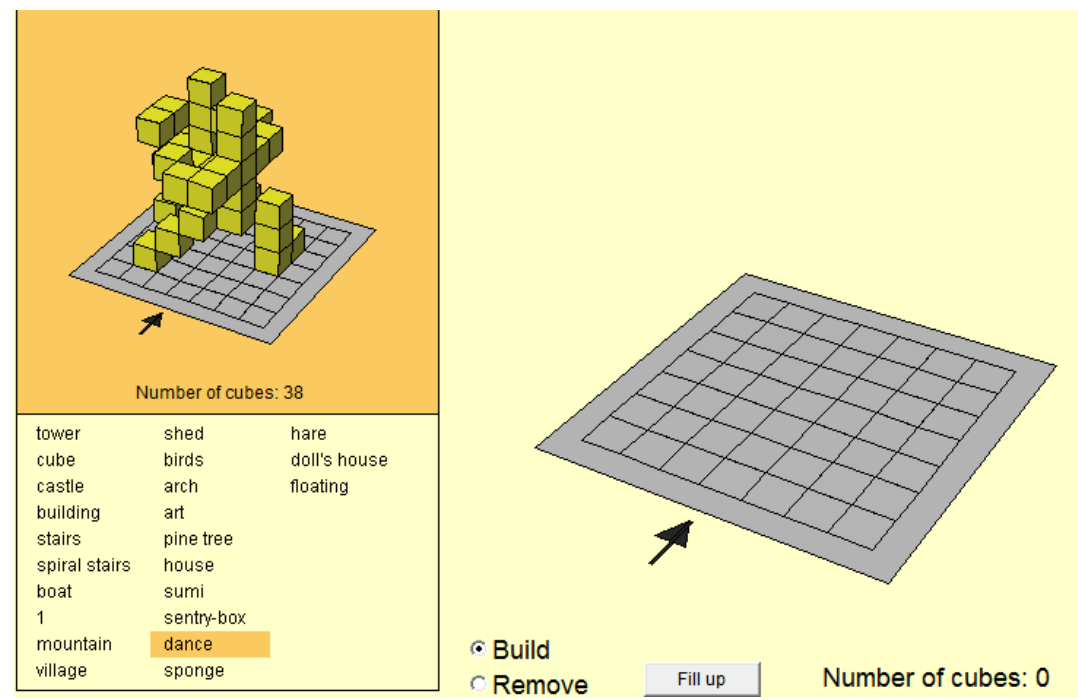

Figura 8. Layout do objeto digital Copy the Building

Esta atividade exigiu atenção e percepção de como a figura foi construída para, posteriormente, representá-la.

Além disso, o aluno B destaca a importância da seta. Esta seta apontada pelo aluno, refere-se à indicação da vista frontal da construção. Isso pode ser conferido nas imagens ao longo deste trabalho.

Sem a seta indicativa, o aluno $\mathrm{C}$ comenta que poderiam existir diversas possibilidades de respostas. Isso porque a seta é o ponto de início para a compreensão das diversas vistas. Ou seja, se a figura for manipulada a seta sempre indicará onde é a vista frontal, que neste caso, significa o ponto-partida ou ponto-referência. Se cada um considerar pontos-partida diferentes, as vistas também serão diferentes.

Além da manipulação do objeto para obter uma representação fiel à imagem original, novamente a questão da captura das telas fez os alunos refletirem sobre os números mínimos de capturas necessárias para cada figura. Notou-se também que os alunos precisaram de mais tempo para a figura dance, dada a complexidade da construção em relação às outras, pois os cubos não estavam todos sobrepostos, o que exigia rotacioná-los de várias maneiras. Nesta etapa, o exercício das três categorias de habilidades espaciais estava em jogo.

$\mathrm{Na}$ terceira atividade, foi solicitado que os alunos representassem na malha quadriculada, a vista superior de determinadas figuras, que agora não estavam mais no objeto digital, na qual permitia a movimentação da construção e, sim, no papel, estáticas. Dessa forma, a habilidade espacial de rotação mental seria fundamental para a solução da atividade. Além disso, os alunos deveriam indicar o número de cubos postos e sobrepostos em cada espaço utilizado na malha, ou seja, a projeção ortogonal codificada superior. 
O resultado da atividade foi positivo, pois percebemos que os alunos conseguiram, em geral $80 \%$ a $100 \%$ de acertos. Quanto aos erros, observamos que muitos alunos tentaram fazer a representação sem situar inicialmente, a localização da visão frontal. Uma estratégia utilizada por alguns alunos foi virar a folha de acordo com a seta do objeto digital. Isso pode ser facilmente identificado pelos números escritos em posição horizontal. "Para fazer deixei a folha virada do mesmo lado, que de um jeito facilitou." (Aluno D).

A questão com maior número de dificuldades foi o sólido abaixo (Figura 9), pelo maior número de cubos utilizados na construção, pela posição, cujo ponto-partida não estava localizado frontalmente na imagem.
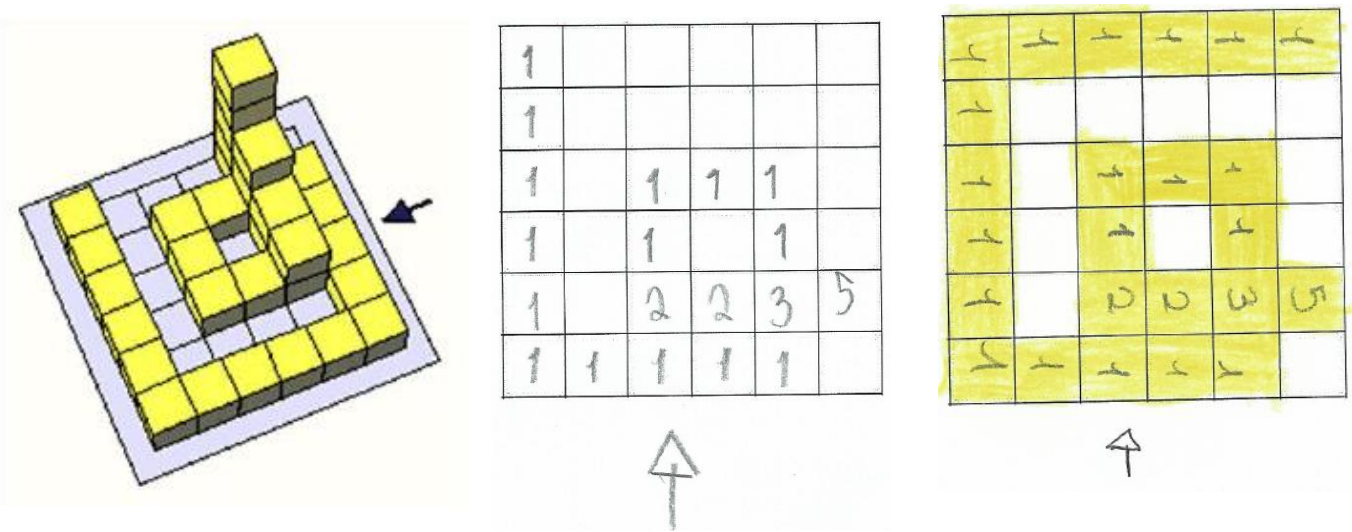

Figura 9. Duas representações dos alunos do sólido à esquerda.

A quarta atividade, realizada com o objeto digital Rotation Game, tinha o intuito de rotacionar uma determinada figura até se chegar à vista solicitada pelo objeto de aprendizagem, conforme ilustra a Figura 10. No total, eram vinte construções com a possibilidade de um erro para cada uma delas. Este objeto de aprendizagem mostrava a pontuação total (score) do aluno e também indicava as questões nas quais o aluno havia se equivocado.

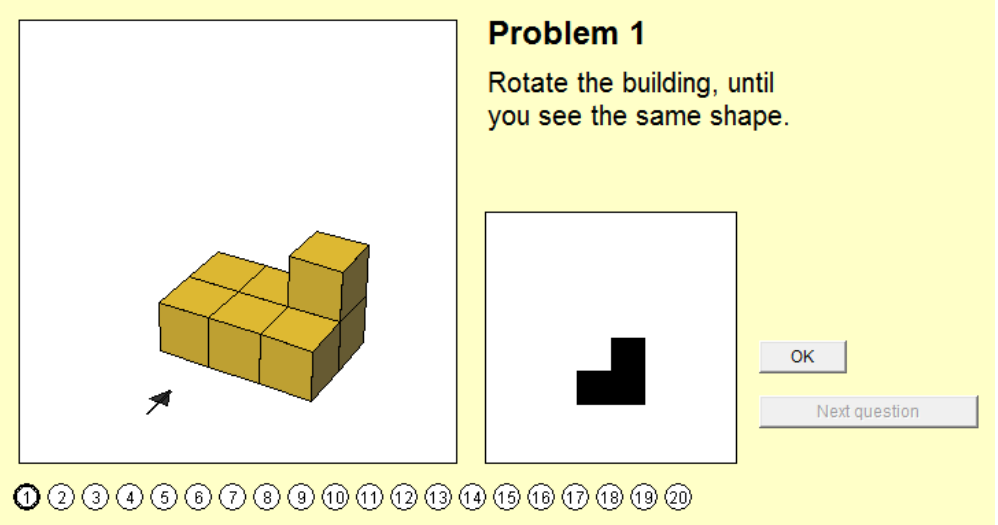

Figura 10. Layout do objeto digital Rotation Game

Esta tarefa possibilitou ao aluno rotacionar as figuras e perceber as diversas visualizações de um mesmo objeto, na medida em que deveria colocá-lo na posição determinada pelo aplicativo. Os alunos, em geral, tiveram êxito na realização desta atividade.

Na quinta atividade, realizada com o objeto digital Building With Three Sides, os alunos realizaram a construção de dez objetos, na qual foram fornecidas três visualizações: superior, frontal e direita. 
Os alunos tiveram que realizar a construção da figura a partir do estabelecimento de relações entre as três vistas dadas, de forma a obter a figura solicitada, conforme Figura 11. Neste caso, tinham a projeção ortogonal como ponto de partida para construção.
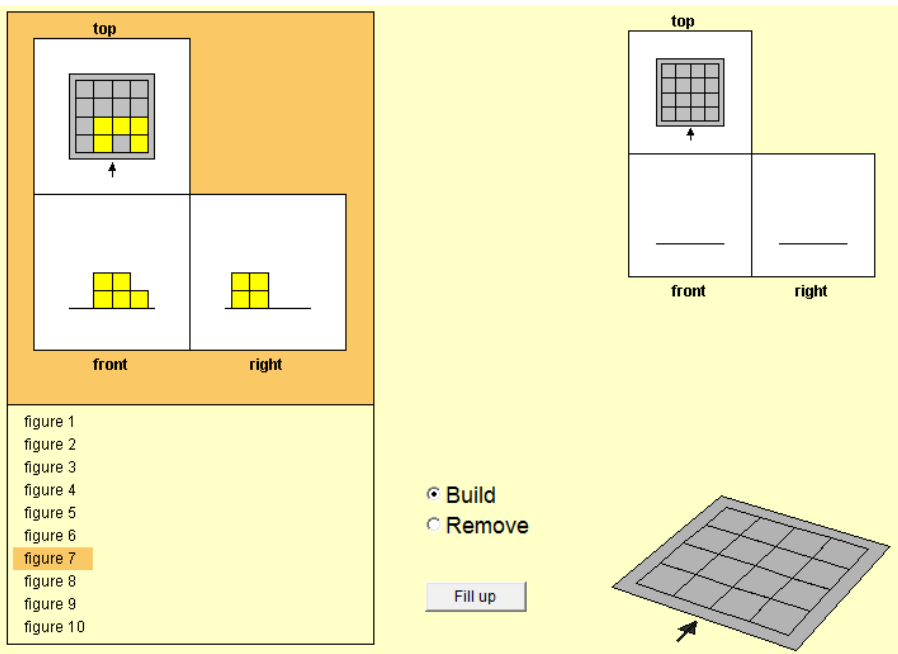

Figura 11. Layout do objeto digital Building With Three Sides

Na sexta atividade, os alunos deveriam identificar quatro vistas de construções dadas: superior, esquerda, direita e frontal (Figura 12).

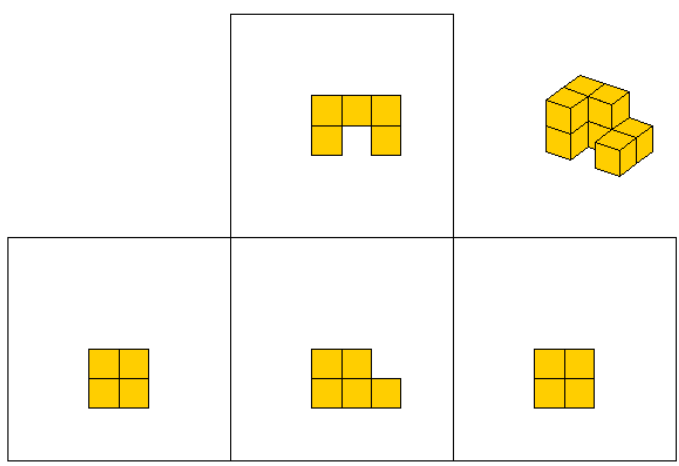

Figura 12. Uma das questões da sexta atividade.

Foi ressaltada a importância de fixar a visão frontal, através da seta, evitando ambiguidades. Segundo os alunos, para resolver esta atividade, foi necessário "imaginar" como se estivessem rotacionando no computador, com base nas atividades anteriores, exigindo a habilidade de rotação mental, a percepção e visualização espacial. O aluno D, diz ter feito um "giro mental" para perceber a quantidade de cubos. O aluno E não encontrou dificuldades, pois se sentiu preparado pelas atividades anteriormente realizadas. Isto significa que, de certa forma, as atividades realizadas estavam proporcionando momentos de desenvolvimento e aprendizagem.

A sétima atividade, realizada com o objeto digital Guess the view, tinha como objetivo identificar qual das vistas de uma determinada figura estava indicada na tela do computador: frontal, superior, inferior, esquerda, direita e traseira. Os alunos poderiam manipular a figura, o que de certa forma facilitava sua resolução, porém, a figura não indicava mais os cubos da construção, como nas atividades anteriores, como ilustra a Figura 13. 
Esta atividade exigiu dos alunos uma análise mais detalhada de cada figura, pois não havia o módulo multicubo. $\mathrm{O}$ aluno $\mathrm{C}$ afirma que "tive que pensar mais e girar bastante a figura até entendê-la". Ou seja, precisou rotacionar inúmeras vezes para estabelecer a relação espacial com a relação plana que no caso nos remete a habilidade de visualização espacial. Já o aluno D comenta: “demorei um pouco pra me achar, pois esquecia de observar a seta" e isso dificultava em descobrir a vista solicitada.

Percebemos que esta atividade desafiou mais os alunos, devido ao módulo multicubo estar ocultado, assim a quantidade de cubo não poderia ser mais referência para realizar esta atividade.

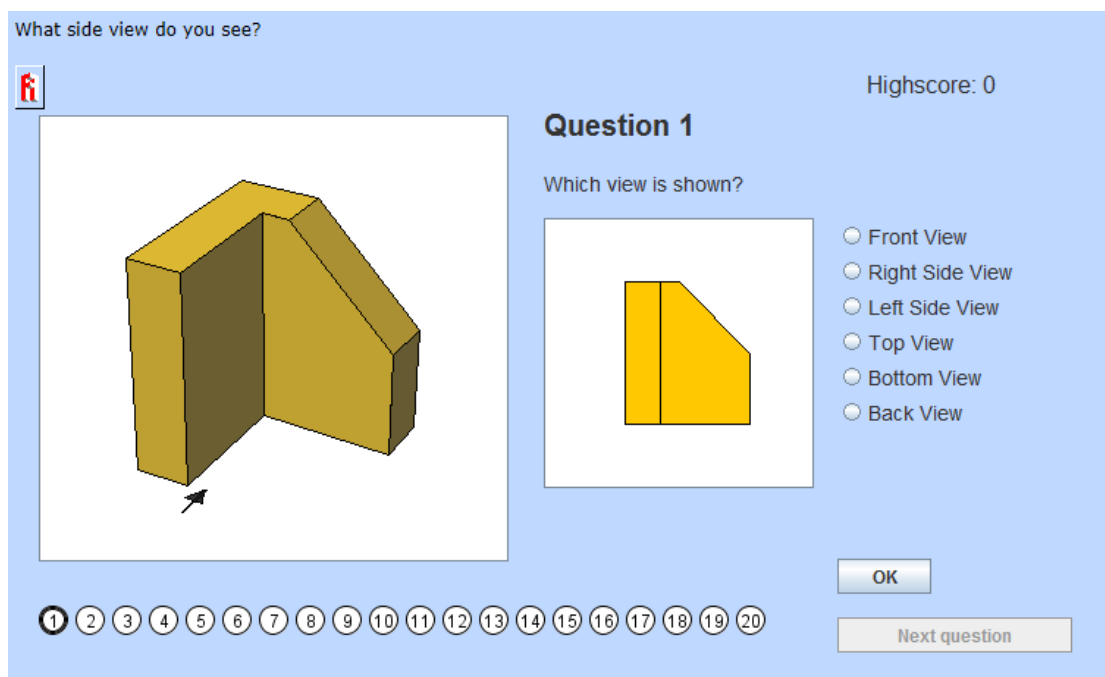

Figura 13. Layout do objeto digital Guess the View

A oitava e última atividade tinha como objetivo que os alunos, sem a manipulação dos objetos, apenas com uma imagem do sólido, pudessem representar as seis vistas (frontal, superior, inferior, esquerda, direita, traseira) de cinco figuras na malha quadriculada.

O resultado desta atividade foi positivo. O maior número representações equivocadas referiu-se a vista inferior. Segundo o aluno $\mathrm{F}$, tais enganos poderia ser o fato desta vista ser pouco trabalhada nas atividades anteriores. $\mathrm{O}$ aluno $\mathrm{H}$ afirma: $a$ figura 3 foi a mais difícil porque a visão superior e inferior são quase a mesma coisa. Para eu conseguir fazê-la, me baseei na atividade 7 e na visão frontal.
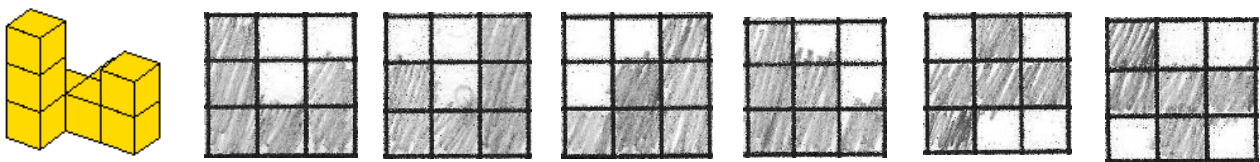

Figura 14. As seis vistas do aluno $\mathrm{H}$ de um dos sólidos. Da esquerda para direita (frontal, traseira, esquerda, direita, superior e inferior).

\section{Considerações Finais}

Segundo Gutierrez (1998), é praticamente unânime entre diversos estudiosos do assunto a necessidade de desenvolver e experimentar atividades que proporcionem aos alunos conexões entre os espaços de duas e três dimensões.

Analogamente com o objetivo deste trabalho, percebemos que os objetos digitais de aprendizagem podem auxiliar os alunos no desenvolvimento de habilidades espaciais. Isto se intensifica se forem desenvolvidas atividades ao longo do Ensino Básico, proporcionando atividades em que a percepção, a rotação e a visualização espaciais sejam exigidas e exploradas. Talvez, as frequentes dificuldades enfrentadas 
pelos alunos no desenvolvimento da Geometria Espacial, no Ensino Médio, poderiam ser evitadas, ou pelo menos, amenizadas.

O objetivo das atividades apresentadas neste artigo foi trabalhar com alunos $6^{\circ}$ ano do Ensino Fundamental, que ainda estão iniciando sua trajetória escolar. Portanto, fica o desafio, para os professores, de desenvolver com seus alunos experiências que explorem as habilidades espaciais, nas diversas faixas etárias e níveis de conhecimento.

As análises das produções e participações dos alunos ainda encontram-se em desenvolvimento. Entretanto, já foi possível perceber que alunos do Ensino Fundamental apresentam potencial para desenvolver estas habilidades e que os objetos digitais de aprendizagem podem auxiliar neste processo.

\section{Referências Bibliográficas}

BASSO, M. V, et al [Org.] Matemática, Mídias Digitais e Didática: tripé para a formação do professor de Matemática. Porto Alegre: Evangraf. 2012. 180 p.

BRASIL. 1998. Parâmetros Curriculares Nacionais ( $5^{\mathrm{a}}$ a $8^{\mathrm{a}}$ séries). Brasília: MEC/SEF.

CHOI, J. Sex differences in spatial abilities in humans: two levels of explanation. In: VOKEY, J.R.; ALLEN, S.W. Psychological Sketches. Department of Psychology and Neuroscience, University of Lethbridge, $7^{\mathrm{a}}$ ed., 2005. Disponível em: <https://www.uleth.ca/dspace/handle/10133/509> Acesso em: 13 jun. 2013.

FIORENTINI, Dario; LORENZATO, Sergio. Investigação em Educação Matemática. Campinas: Autores associados, 2006.

GRAVINA, M. A. Os ambientes de Geometria Dinâmica e o Pensamento HipotéticoDedutivo. 2001. 262f. Tese (Doutorado em Informática na Educação). UFRGS. Porto Alegre, 2001.

GUTIÉRREZ, A. Las representaciones planas de cuerpos 3-dimensionales en la enseñanza de la geometria espacial. Revista EMA 3.3, Colômbia, 1998. Disponível em: <http://www.uv.es/gutierre/archivos1/textospdf/Gut98a.pdf> Acesso em: 7 mai. 2013.

GUTIÉRREZ, A. Procesos y habilidades en visualización espacial. Memorias Del Tercer Simposio Internacional sobre Investigación en Educación Matemática: Geometria. Valência 1992. Disponível em: <http://www.uv.es/gutierre/archivos1/textospdf/Gut92b.pdf>. Acesso em: 7 mai. 2013

LOHMAN, D. F. Spatial Ability and G. Paper presented at the first Spearman Seminar, University of Plymouth, 1993.

LOVELL, K. O desenvolvimento dos conceitos matemáticos e científicos na criança. Trad. AuripheboBerrance Simões. Porto Alegre: Artes Médicas, 1988. 134 p.

NEVES, J. L. Pesquisa qualitativa - características, usos e possibilidades. Caderno de pesquisas em administração, São Paulo, V. 1, $\mathrm{n}^{\circ} 3,2^{\circ}$ Sem./1996. Disponível em: <www.ead.fea.usp.br/cad-pesq/arquivos/C03-art06.pdf> Acesso em: 3 de nov. 2012.

PAPERT, S. M. A máquina das crianças: repensando a escola na era da informática. Trad. Sandra Costa. Porto Alegre: Artes Médicas, 2008, 210 p.

SILVA, D. V. da. Habilidades espaciais, raciocínio e desempenho em tecnologias da informação: estudo correlacional com Ensino Médio. Dissertação (mestrado). Universidade de São Francisco. Itatiba, 2010. 